\title{
Interstitial deletion, del(4)(q33q35.1), in a mother and two children
}

\author{
MERRYL A CURTIS*, R A SMITH*, JO SIBERT $\dagger$, AND \\ HELEN E HUGHES* \\ *Institute of Medical Genetics and tDepartment of Child Health, University of Wales College of Medicine, \\ Cardiff CF4 $4 X N$.
}

SUMMARY The inheritance of autosomal deletions from affected parents has only rarely been reported. We report an unbalanced interstitial deletion, del(4)(q33q35.1), in a mother and two male offspring. The mother and older sib are mentally retarded but have only mild dysmorphic features. The younger sib, at five months, is showing signs of developmental delay. All three patients show some abnormalities in common with cases that have terminal deletions of $4 \mathrm{q}$ with breakpoints at $4 q 33$, but in general exhibit less severe abnormalities. The family illustrates the importance of detailed cytogenetic analysis of children with developmental delay who do not display major dysmorphic features.

\section{Case report}

The male proband, the first child of a 23 year old mother and her unrelated 26 year old husband, was delivered at 41 weeks' gestation by emergency caesarean section for antepartum haemorrhage. Birth weight was $3275 \mathrm{~g}$ (>10th centile), OFC $36 \mathrm{~cm}$ (>50th centile), and crown-rump length $47 \mathrm{~cm}$ ( $<10$ th centile). Apgar scores were 9 at one and five minutes. The neonatal course was uneventful. Early developmental milestones were said to have been within normal limits, but at two years he failed a routine Denver developmental screening assessment. Formal developmental assessment at 26 and 35 months confirmed the presence of global developmental delay with more marked delay in language development (table). Formal audiometric assessment was normal. Visual assessment showed the presence of Duane's syndrome in the right eye. Physical examination at three years showed only mild dysmorphic features, including a long philtrum with thin upper lip and borderline low set, posteriorly rotated ears, and confirmed that there were no gross physical abnormalities (fig 1). The left testis was

Received for publication 2 May 1989. Accepted for publication 3 May 1989.
TABLE Developmental quotients of proband on Griffiths Mental Development Scales.

\begin{tabular}{lll}
\hline Subscale & \multicolumn{2}{l}{ Age at assessment } \\
\cline { 2 - 3 } & 26 months & 35 months \\
\hline Locomotor scale & 87 & 75 \\
Personal/social & 76 & 69 \\
Hearing/speech & 74 & 59 \\
Hand-eye coordination & 87 & 68 \\
Performance & 93 & 62 \\
\hline
\end{tabular}

undescended and he had a right sixth nerve palsy. His general health was good. At five years he has continued to have learning difficulties and behavioural problems and has been placed in a school for children with special educational needs.

He was referred for cytogenetic investigation at three years. High resolution cytogenetic analysis showed a small interstitial deletion of the distal region of the long arm of chromosome 4 . This was interpreted as del(4)(q33q35.1) (fig 2).

Family studies showed the same deletion in the proband's mother (fig 1). Her physical features were unremarkable other than upward slanting palpebral fissures, but she had attended a school for the educationally subnormal and could neither read nor write. There was no evidence in either the mother or the child that the deleted material was present in any other chromosome. The maternal grandparents were not available for study. The father and a two year old brother had normal karyotypes. The development of the younger brother was normal. The family were given a $50 \%$ recurrence risk, but prenatal cytogenetic analysis was declined in a subsequent pregnancy three years later.

A third male infant was delivered at 38 weeks' gestation by elective caesarean section. Birth weight was $3290 \mathrm{~g}$ (50th centile), OFC $36 \mathrm{~cm}$ (>50th centile), and crown-rump length $47 \mathrm{~cm}(>10$ th centile). Apgar scores were 8 and 9 at one and five minutes respectively. Cytogenetic analysis of cord blood obtained at delivery confirmed the presence of the deleted chromosome 4 found in his affected older brother and mother. He was admitted to hospital at the age of nine weeks with bronchiolitis 

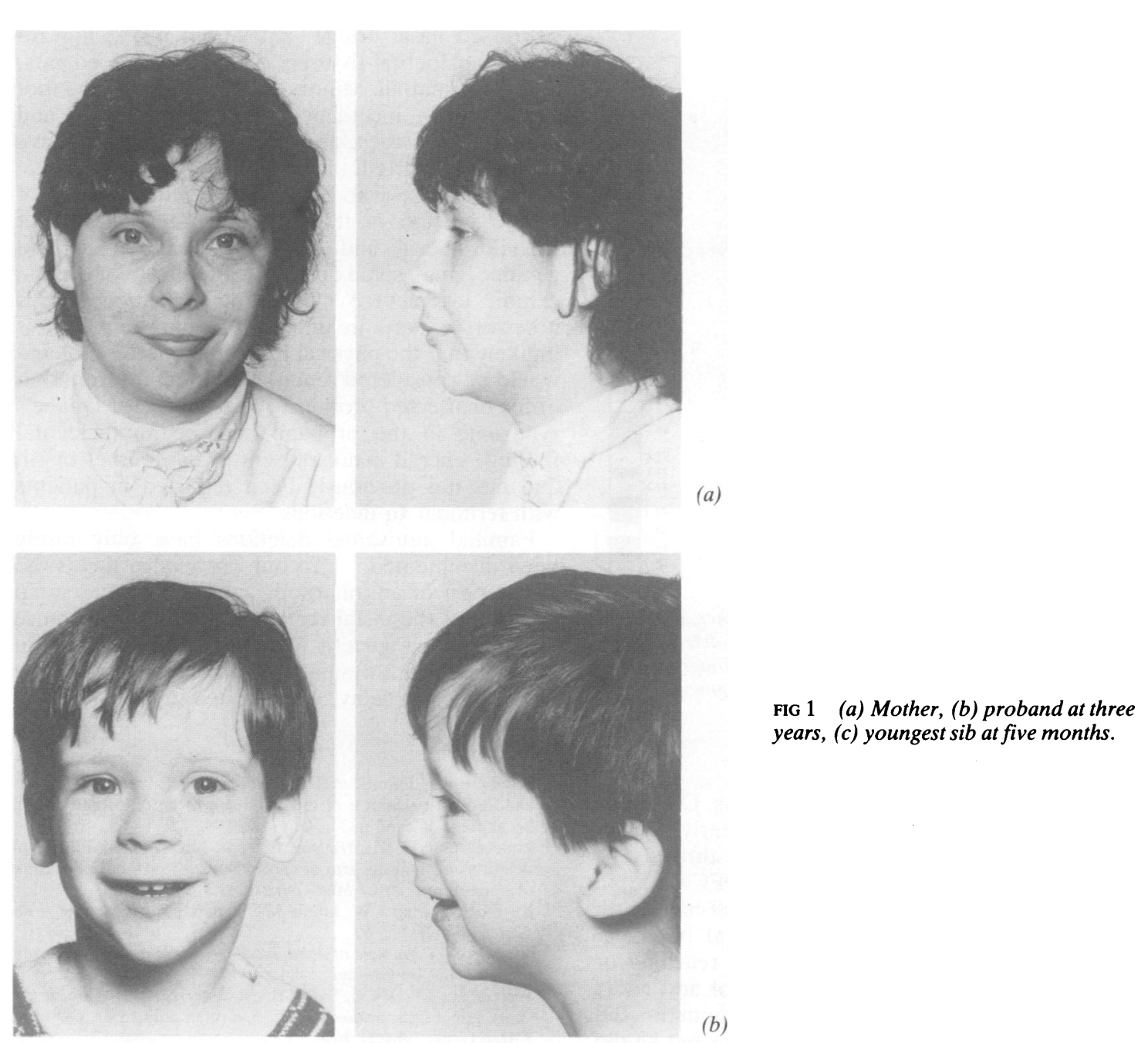

(b)
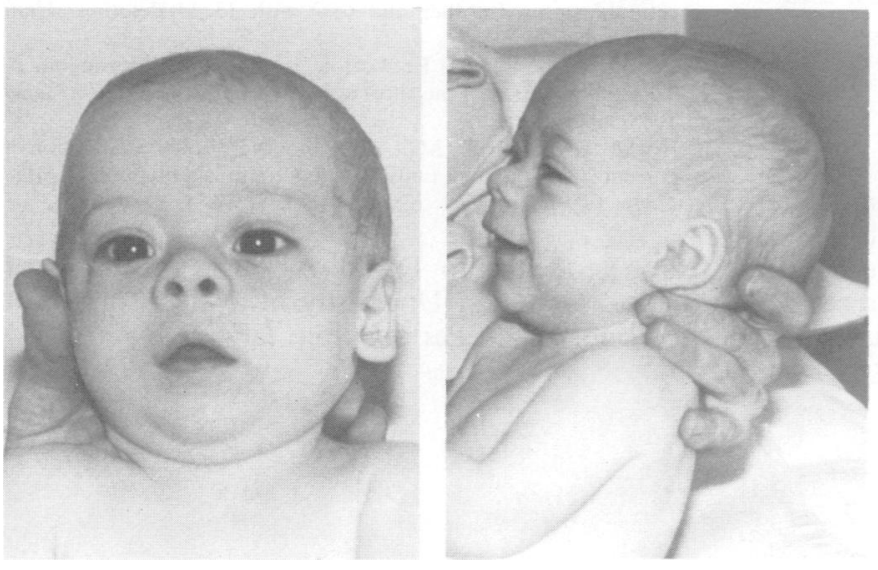

(c)

FIG 1 (a) Mother, (b) proband at three 


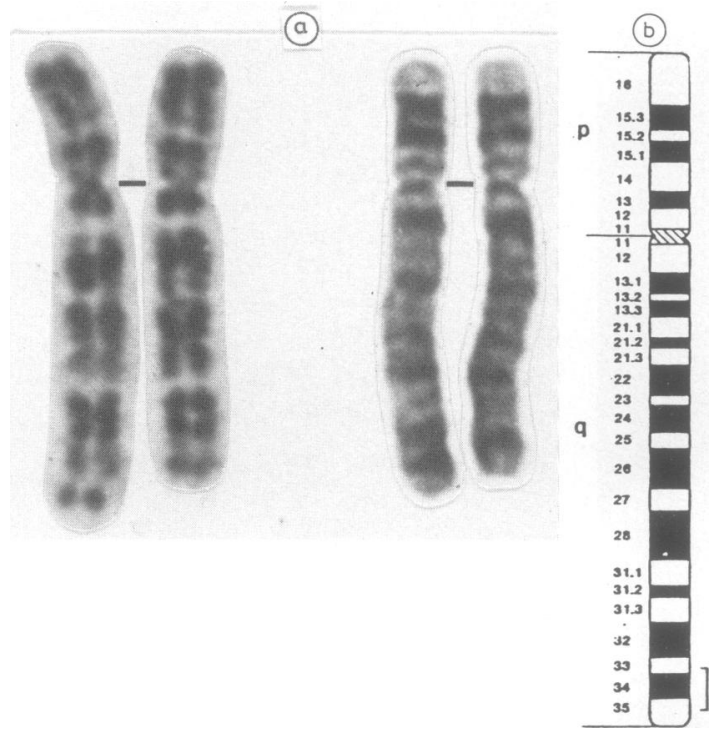

FIG 2 (a) Chromosome 4 pairs from the mother, RBG banding (left) and GTG banding (right). The deleted chromosome is on the right in each pair. (b) Diagram of chromosome 4 showing location of deleted segment ( $G$ banding).

resulting from respiratory syncytial virus. On examination at five months he was showing early signs of developmental delay and failure to thrive. His weight was $5.8 \mathrm{~kg}$ (<10th centile), OFC $43.5 \mathrm{~cm}$ (50th centile), and crown-rump length $60 \mathrm{~cm}(<10$ th centile). He was turning to sound and babbling, holding with a simple grasp, but not reaching or transferring. He had poor head control and could not roll from side to back. Physical examination did not show any major dysmorphic features but he did have a long, flat philtrum, anteverted nares, and a proximally placed right fifth toe (fig 1).

\section{Discussion}

Distal deletions of the long arm of chromosome 4, with breakpoints at $4 \mathrm{q} 33$, are well documented and a recognisable syndrome resulting from $\operatorname{del}(4)(\mathrm{q} 33)$ has been defined. ${ }^{12}$ The main features are mental and growth retardation and a characteristic craniofacial dysmorphism including absent glabellar angle, depressed nasal bridge, anteverted nares, upward slanting palpebral fissures, abnormally shaped ears, and micrognathia. Minor and variable hand and foot abnormalities, including cleft hand, syndactyly, and malpositioned toes, and mild cardiac defects have also been reported.

Our patients, who have an interstitial deletion of $ळ$ only a portion of this region, comprising $7 \%$ of $\vec{\circ}$ chromosome 4 and $0.5 \%$ of the total haploid genome, share some of these features, but in general exhibit less severe clinical malformations. It is noteworthy that, in unbiased circumstances, it is unlikely that the physical phenotype of the proband would be considered remarkably different from that of his unaffected brother. The presence of Duane's syndrome in the proband may be an incidental finding, since it is not present in the mother or sib and has not previously been reported in patients with terminal $4 \mathrm{q}$ deletions.

Familial autosomal deletions have only rarely been documented..$^{3-8}$ To our knowledge this is the first report of an inherited, unbalanced, interstitial deletion of the distal region of $4 \mathrm{q}$. The importance of detailed cytogenetic analysis of children who do not have obvious dysmorphic features, but who have developmental delay, is illustrated in this family.

\section{References}

1 Tomkins DJ, Hunter AGW, Uchida IA, Roberts MH. Two children with deletion of the long arm of chromosome 4 with breakpoint at band q33. Clin Genet 1982;22:348-55.

2 Lin AE, Garver KL, Diggans G, et al. Interstitial and terminal deletions of the long arm of chromosome 4: further delineation of phenotypes. Am J Med Genet 1988;31:533-48.

${ }^{3}$ Kushnick T, Rao KW, Lamb AN. Familial 5p-syndrome. Clin Genet 1984;26:472-6.

${ }_{4}^{4}$ Schinzel A. Catalogue of unbalanced chromosome aberrations in man. Berlin: de Gruyter, 1984.

5 Walker JL, Blank CE, Smith BAM. Interstitial deletion of the short arm of chromosome 5 in a mother and three children. J Med Genet 1984;21:465-7.

${ }^{6}$ Fukushima Y, Kuroki Y, Ito T, Kondo I, Nishigaki I. Familial retinoblastoma (mother and son) with 13q14 deletion. Hum Genet 1987;77:104-7.

7 Baccichetti C, Lenzini E, Artifoni L, Caufin D, Marangoni P. Terminal deletion of the short arm of chromosome 5. Clin Genet 1988;34:219-23.

8 Hockey KA, Mulcahy MT, Montgomery P, Levitt S. Deletion of $\mathbb{N}$ chromosome $5 \mathrm{q}$ and familial adenomatous polyposis. J Med Genet 1989;26:61-2.

Correspondence to $\operatorname{Dr} M$ A Curtis, Institute of Medical Genetics, University of Wales College of Medicine, Heath Park, Cardiff CF4 4XN. 